Bull. Chem. Soc. Ethiop. 2013, 27(2), 221-232.

Printed in Ethiopia

DOI: http://dx.doi.org/10.4314/bcse.v27i2.7

ISSN 1011-3924

(c) 2013 Chemical Society of Ethiopia

\title{
SYNTHESIS, CHARACTERIZATION AND PHOTOCATALYTIC ACTIVITIES OF Ag-N-CODOPED ZnO NANOPARTICLES FOR DEGRADATION OF METHYL RED
}

\author{
Tesfay Welderfael ${ }^{1}$, O.P. Yadav ${ }^{1}$, Abi M. Taddesse ${ }^{1^{*}}$ and Jyotsna Kaushal ${ }^{2}$ \\ ${ }^{1}$ Chemistry Department, Haramaya University, P.B. Box 138, Dire Dawa, Ethiopia \\ ${ }^{2}$ Chitkara Institute of Engineering and Technology, Jhansla (Rajpura) Panjab, India
}

(Received February 16, 2012; revised January 15, 2013)

\begin{abstract}
Ag-N-codoped zinc oxide nanoparticles were synthesized by a one-step impregnation of Ag in $\mathrm{N}$-doped $\mathrm{ZnO}$ nanoparticles. The morphologies and structures of the as-synthesized nanomaterials were investigated by using X-ray diffraction (XRD), transmission electron microscopy (TEM), and UV-Vis spectrophotometric techniques. Photocatalytic degradation of methyl red dye using synthesized photocatalysts was studied under solar as well as UV irradiations. Modified zinc oxide photocatalysts showed higher photocatalytic activity compared to pure zinc oxide both under solar as well as UV irradiations. Calcined zinc oxide shows better photocatalytic activity than commercial zinc oxide under both solar and UV irradiations. Highest catalytic activity of Ag-N co-doped zinc oxide (ANZ) among the undoped, Ag-doped and N-doped photocatalysts was attributed to the lower rate of recombination of the photogenerated electrons and holes as well as its lower band gap energy. Photocatalytic degradation of methyl red dye follows pseudo first order kinetics for all the nanoparticles so-obtained.
\end{abstract}

KEY WORDS: Nanoparticles, Photocatalysis, Zinc oxide, Impregnation, Methyl red

\section{INTRODUCTION}

The uncontrolled release of colored waste water contaminated with dyes from textile, paper, rubber and plastic industries have led to serious environmental contamination [1]. These adversely affect the quality of water, inhibit sunlight penetration and reduce photosynthetic reactions. In addition, some dyes are either toxic or carcinogenic [2]. Currently available water treatment technologies either concentrate the pollutants present by transferring them to other phases (adsorption or coagulation) or involve high operating costs with possible generation of toxic secondary pollutants into the ecosystem (sedimentation, filtration, chemical and membrane technologies) [3].

Recent studies have shown that heterogeneous semiconductor photocatalysis can be an alternative to conventional methods for the removal of dye pollutants from water [4]. When semiconductors are illuminated with an appropriate radiation source, electron/hole pairs are produced with electrons promoted to the conduction band leaving behind positive holes in the valence band. The generated electron/hole pairs induce a complex series of reactions that can result in the complete degradation of organic pollutants such as dye adsorbed on the semiconductor surface [5].

Zinc oxide is a potential photocatalyst which has drawn great attention in research and industries in recent years owing to its powerful oxidation capability, nontoxicity, chemical stability, and low cost [6]. However, the photocatalytic activity of $\mathrm{ZnO}$ is limited to irradiation wavelengths in the $\mathrm{UV}$ region because $\mathrm{ZnO}$ semiconductor has a wide band-gap of about $3.3 \mathrm{eV}$ and can only absorb UV light with wavelengths below $387 \mathrm{~nm}$ [7]. The fast recombination rate of the photogenerated electron-hole pairs also hinders the industrial application of this semiconductor [8].

Considerable efforts have been made to modify $\mathrm{ZnO}$ nanoparticles in order to improve its catalytic efficiency in the visible-light region. The advantages of photocatalysts modifications

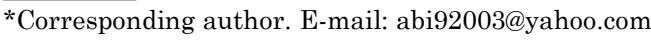


are to delay electron-hole recombination, to broaden the absorption spectrum, to facilitate some specific reactions on the surface of catalysts [7] and to improve photostability [8]. To overcome the problems of anodic photocorrosion and instability of zinc oxide in acidic or alkaline media, doping of transition metals like silver, palladium, platinum and gold with $\mathrm{ZnO}$ may prove beneficial. Doping of such transition metals also will reduce the electron-hole recombination. Another limitation of $\mathrm{ZnO}$ is its wide band gap energy $(=3.2 \mathrm{eV})$ which limits light absorption only in the UV region. A possible strategy to extend zinc oxide photo-absorption to visible light may be the modification of its valance band position by nonmetals doping such as nitrogen, fluorine, sulfur, phosphorous etc. Among the nonmetals, $\mathrm{N}$ is widely acceptable, owing to its compatible size to $\mathrm{O}$ and the fact that it has the smallest ionization energy [9]. The doped nonmetal in $\mathrm{ZnO}$ may cause its band gap narrowing thus shifting the photoabsorption edge of zinc oxide to visible region. Many methods such as template method [10], chemical-precipitation [11], thermal oxidation process [12], hydrothermal synthesis [13], sol-gel method [14], microwave radiation [15], and laser-induction [6] have been used to successfully synthesize the $\mathrm{Ag}$ doped $\mathrm{ZnO}$ nanocrystals. Methods such as molecular beam epitaxy, pulsed laser ablation, and chemical vapor deposition have been utilized to dope $\mathrm{N}$ into $\mathrm{ZnO}$ [8].

There are some literature reports related to the synthesis of $\mathrm{Ag}$ doped $\mathrm{ZnO}$ nanocatalysts and $\mathrm{N}$-doped $\mathrm{ZnO}$ powder. However, reports related to the synthesis of $\mathrm{Ag}-\mathrm{N}$-codoped $\mathrm{ZnO}$ are scant. The only report found, to the researchers' knowledge is $\mathrm{N}$ doped $\mathrm{ZnO} / \mathrm{Ag}$ composite reported by $\mathrm{Li}$ et al. [8]. Here, we described a very simple and rapid method to synthesize nanocrystalls of zinc oxide and Ag-N co-doped zinc oxide, using a technique different from the approaches reported above. The as-synthesized samples are characterized using XRD, TEM, and $\mathrm{UV}-\mathrm{Vis}$ techniques. The photocatalytic properties of Ag-N-codoped nanoparticles were evaluated through the degradation of methyl red solutions initiated by UV and solar radiation.

\section{EXPERIMENTAL}

\section{Materials}

All the chemicals used were analytical grade and used in this experiment without further purification. The chemicals used were zinc acetate dihydrate $\left(\mathrm{Zn}\left(\mathrm{CH}_{3} \mathrm{COO}\right)_{2} .2 \mathrm{H}_{2} \mathrm{O},>99.5 \%\right.$, from Fluka), sodium hydroxide $(\mathrm{NaOH}, 98 \%)$, ethanol $\left(\mathrm{CH}_{3} \mathrm{CH}_{2} \mathrm{OH}, 97.9 \%\right)$, silver nitrate $\left(\mathrm{AgNO}_{3}, 99.9 \%\right.$, Blulux $)$, urea $\left(\left(\mathrm{NH}_{2}\right)_{2} \mathrm{CO}\right.$, Extra pure Blulux $)$, sodium dodecyl sulfate, $\left(\mathrm{C}_{12} \mathrm{H}_{25} \mathrm{NaO}_{4} \mathrm{~S}\right.$, Fluka), methyl red $\left(\mathrm{C}_{15} \mathrm{H}_{15} \mathrm{~N}_{3} \mathrm{O}_{2}\right.$, Berck Scientific Supplies). The structural formula of methyl red is shown in Figure 1.

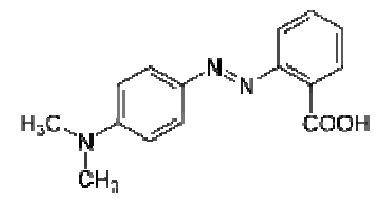

Figure 1. Structural formula of methyl red.

\section{Preparation of $\mathrm{ZnO}$ nanoparticles}

Zinc acetate dihydrate $\left(\mathrm{Zn}\left(\mathrm{CH}_{3} \mathrm{COO}\right)_{2} .2 \mathrm{H}_{2} \mathrm{O}\right)(131.6 \mathrm{~g})$ was added to $3 \mathrm{~L}$ of deionized water under vigorous stirring till homogeneous solution was obtained. Then $172.8 \mathrm{~g}$ of SDS and 0.2 $\mathrm{M}$ of sodium hydroxide were added into the above solution under continuous stirring till $\mathrm{pH}$ value reached 12 and heated at $160{ }^{\circ} \mathrm{C}$ for $14 \mathrm{~h}$ in an oven. The precipitates were recovered by 
centrifugation and washed with deionized water and ethanol several times [16]. The product was dried at $60{ }^{\circ} \mathrm{C}$ for $3 \mathrm{~h}$ and labelled as uncalcined zinc oxide $(\mathrm{Znc})$. A portion of this product $(10 \mathrm{~g} \mathrm{Znc})$ was calcined at $400{ }^{\circ} \mathrm{C}$ for $4 \mathrm{~h}$, cooled to room temperature, ground in agate mortar and labelled as calcined zinc oxide $(\mathrm{Zc})$.

Preparation of silver-doped $\mathrm{ZnO}$

The Ag-doped $\mathrm{ZnO}$ was prepared in a one step impregnation method. $10 \mathrm{~mL}$ of silver nitrate $(0.18 \mathrm{M})$ was added to $10 \mathrm{~g}$ of uncalcined zinc oxide $(\mathrm{Znc})$. The sample was agitated and heated at $110{ }^{\circ} \mathrm{C}$ for $30 \mathrm{~min}$ and then calcined at $400{ }^{\circ} \mathrm{C}$ for $4 \mathrm{~h}$, ground in an agate mortar [17]. The product obtained was labelled as silver-doped zinc oxide (AZ).

\section{Preparation of nitrogen-doped $\mathrm{ZnO}$}

The $\mathrm{N}$-doped $\mathrm{ZnO}$ was synthesized in a solvent free reaction. $20 \mathrm{~g}$ of uncalcined zinc oxide was added to $40 \mathrm{~g}$ of urea and grinded in an agate mortar. The mixture was calcined in a ceramic crucible at $400{ }^{\circ} \mathrm{C}$ for $4 \mathrm{~h}$ and cooled [18]. The product was ground to fine powder and labelled as nitrogen-doped zinc oxide (NZ).

Preparation of silver-nitrogen co-doped $\mathrm{ZnO}$

The Ag-N-codoped $\mathrm{ZnO}$ nanopowder was prepared in a one-step impregnation method. $10 \mathrm{~mL}$ of silver nitrate $(0.18 \mathrm{M})$ was transferred into ceramic crucible containing $10 \mathrm{~g}$ of nitrogen doped zinc oxide (NZ), and was agitated with glass rod. The crucible was put in an oven for drying at $110{ }^{\circ} \mathrm{C}$ for $30 \mathrm{~min}$. The dried powder was calcined at $400{ }^{\circ} \mathrm{C}$ for $4 \mathrm{~h}$, cooled to room temperature and was ground in an agate mortar. The product was labelled as silver-nitrogen codoped zinc oxide (ANZ).

\section{Characterization of the as-synthesized photocatalysts}

$U V$-Visible diffuse absorption measurements. To observe the absorption edge of the assynthesized photocatalysts, UV-Vis diffuse absorption spectra was recorded using spectrophotometer (Perkin Elmer model: lambda-SP65). $0.1 \mathrm{~g}$ of the photocatalyst was dispersed in $50 \mathrm{~mL}$ of deionized water and the absorbance data was recorded as a function of wavelength.

$X$-ray diffraction (XRD) measurement. For determining the crystallite size and structure of assynthesized photocatalysts, X-ray diffraction (XRD) pattern were obtained by means of X-ray diffractometer (Model: Bruker D8 AXS GmbH ) using a Cu target $\mathrm{K}_{\alpha}\left(\lambda=1.5406 \mathrm{~A}^{0}\right)$. The measurements were carried out at room temperature using accelerating voltage $45 \mathrm{kV}$ and applied current $40 \mathrm{~mA}$. It was operated in the step scan rate at $0.02^{0}$ (step time: $1 \mathrm{~s} ; 2 \theta$ range: $\left.5.0-79.9^{0}\right)$.

Transmission electron microscopic (TEM) measurement. A drop of photocatalyst suspension in ethanol was spread over a carbon-coated copper grid. The solvent was allowed to evaporate. TEM images of photocatalyst particles were obtained using a transmission electron microscope (JEOL model JEM-2000 FX) at an accelerating voltage: $100 \mathrm{kV}$

Photocatalytic degradation studies

MR aqueous solution was employed as a representative indicator to evaluate the UV photocatalytic activity of the as-prepared samples. Experiments were carried out as follows: 0.2 
$\mathrm{g}$ of photocatalyst was ultrasonically dispersed in MR aqueous solution and magnetically stirred in the dark for $40 \mathrm{~min}$ to ensure the adsorption/desorption equilibrium of MR aqueous solution with the catalyst [19]. The mixture was then loaded in an open beaker and continuously stirred during the exposure to UV light from a low-pressure lamp (Philips $12 \mathrm{~W}, 230 \mathrm{~V}$ and $50 \mathrm{~Hz}$; the strongest emission at $254 \mathrm{~nm}$ ) positioned parallel to reactor, emitting light intensity of $6.4 \times$ $10^{-2} \mathrm{~W} / \mathrm{cm}^{2}$. UV-Vis absorption spectra of samples were measured at regular intervals of $20 \mathrm{~min}$ to monitor the reaction of MR aqueous solution decolorization, and the absorption range of 200-800 $\mathrm{nm}$ was recorded as a function of irradiation time. The $10 \mathrm{~mL}$ suspension withdrawn at 20 min interval was centrifuged at $2500 \mathrm{rpm}$ for $15 \mathrm{~min}$ and filtered using Whatman No. 1 filter paper to remove the catalyst particles, if any, before recording the absorbance at $\lambda_{\max }=522 \mathrm{~nm}$ using UV/Vis spectrophotometer (SP65). Percentage degradation of MR was calculated using the relation:

$\%$ degradation $=\left[\left(\mathrm{A}_{0}-\mathrm{A}_{\mathrm{t}}\right) / \mathrm{A}_{0}\right] \times 100$

where $\mathrm{A}_{0}$ is absorbance of dye at initial stage, $\mathrm{A}_{t}$ is absorbance of dye at time "t".

\section{RESULT AND DISCUSSION}

Synthesis of zinc oxide

The following chemical reactions are involved during the synthesis of $\mathrm{ZnO}$ nanoparticles [16]:

$$
\begin{aligned}
& \mathrm{Zn}\left(\mathrm{CH}_{3} \mathrm{COO}\right)_{2} \cdot 2 \mathrm{H}_{2} \mathrm{O}+2 \mathrm{NaOH} \stackrel{\mathrm{C}_{12} \mathrm{H}_{25} \mathrm{SO}_{4} \mathrm{Na}}{\longrightarrow} \mathrm{Zn}(\mathrm{OH})_{2}+2 \mathrm{CH}_{3} \mathrm{COO}^{-}+2 \mathrm{Na}^{+}+2 \mathrm{H}_{2} \mathrm{O} \\
& \mathrm{Zn}(\mathrm{OH})_{2} \underset{\text { for } 14 \mathrm{hrs}}{\longrightarrow} \mathrm{ZnO} \text { (nanoparticles) }+\mathrm{H}_{2} \mathrm{O}
\end{aligned}
$$

At the end of the reaction, sodium dodecyl sulfate (SDS) and $\mathrm{CH}_{3} \mathrm{COONa}$ were eliminated during washing of $\mathrm{Zn}(\mathrm{OH})_{2}$. The final yield of $\mathrm{ZnO}$ was $90 \%$.

\section{$X R D$}

XRD pattern of Zc, AZ, NZ, and ANZ are presented in Figure 2. The peaks at $2 \theta$ values of $31.76^{\circ}, 34.43^{\circ}, 36.25^{\circ}, 47.56^{\circ}, 56.62^{\circ}, 62.86^{\circ}, 66.38^{\circ}, 67.97^{\circ}$, and $69.10^{\circ}$ observed in the XRD spectra of ANZ (Figure 2-d) are indicative of the typical hexagonal wurtzite structure of $\mathrm{ZnO}$ (according to JCPDS no. 04-0783) [20], while those of $38.12^{\circ}, 44.31^{\circ}$, and $64.45^{\circ}$ can be indexed to face centered-cubic (fcc) metallic Ag. Similar diffraction pattern is reported by Li $e t$ al. [8] for $\mathrm{N}$-doped $\mathrm{Ag} / \mathrm{ZnO}$ nanocomposite. Observed pattern of diffraction peaks for calcined $\mathrm{ZnO}$ (Figure 2-a) and silver-doped $\mathrm{ZnO}$ (Figure 2-b) are identical in respect of their positions as well as intensities. Absence of such shifts in the recorded XRD indicates the segregation of Ag particles in the grain boundaries of $\mathrm{ZnO}$ or incorporation of only an insignificant quantity in the substitutional $\mathrm{Zn}$ site [15]. However, the latter possibility is unlikely due to the difference in ionic radii between $\mathrm{Ag}^{+}(1.22 \AA)$ and $\mathrm{Zn}^{2+}(0.72 \AA)$; the silver particles preferentially choose to segregate around the $\mathrm{ZnO}$ grain boundaries. Diffraction peaks for $\mathrm{N}$-doped $\mathrm{ZnO}$ (Figure 2-c) are more resolved compared to those in the spectra of $\mathrm{ZnO}$ suggesting that doped nitrogen replaces some of the oxygens in $\mathrm{ZnO}$ crystal lattice.

The average crystalline sizes of the as-sythesized photocatalysts were obtained using Scherrer equation [18]:

$\mathrm{D}=[\mathrm{K} \lambda(\beta \operatorname{Cos} \theta)]$ 
where $\mathrm{D}$ is the crystallite size in $\mathrm{nm}, \mathrm{K}$ is the shape factor constant and taken as $0.9 ; \beta$ is the full width at half maximum (FWHM) in radians; $\lambda$ is the wavelength of the X-ray $(=0.15406 \mathrm{~nm})$ for $\mathrm{Cu}$ target $\mathrm{K}_{\alpha}$ radiation and $\theta$ is the Bragg's angle. The calculated average crystallite sizes (D) of as-synthesized photocatalysts are recorded in Table 1. The order of crystallite size of assynthesized photocatalysts was: Zc $~ A Z>A N Z>N Z$. Lower size of ANZ than Zc and AZ may be due to the $\mathrm{N}$ doping as the $\mathrm{N}$ doped $\mathrm{ZnO}$ exhibited the lowest crystal size.

a

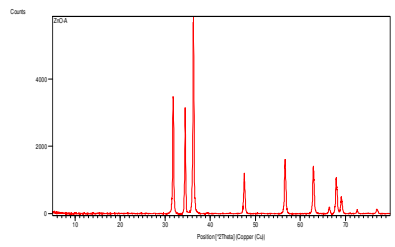

C

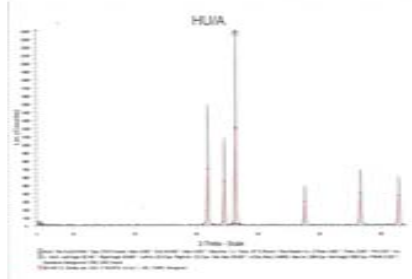

b

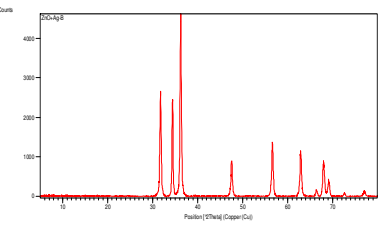

d

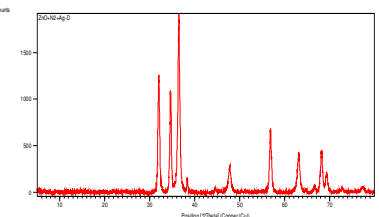

Figure 2.XRD spectra: (a) calcined zinc oxide (Zc), (b) silver-doped zinc oxide (AZ), (c) nitrogen doped zinc oxide (NZ), (d) silver-nitrogen co-doped zinc oxide (ANZ).

Table 1. Average crystallite size (D) of as-synthesized photocatalysts.

\begin{tabular}{|c|c|c|c|}
\hline Sample & $2 \theta$ (degree) & $\beta$ (radians) & $\mathrm{D}(\mathrm{nm})$ \\
\hline Zc & 36.2132 & 0.0032 & $45(42)^{*}$ \\
\hline AZ & 36.2189 & 0.0031 & $47(44)$ \\
\hline NZ & 36.2193 & 0.0171 & $33(20)$ \\
\hline ANZ & 36.4944 & 0.0064 & $23(16)$ \\
\hline
\end{tabular}

$\mathrm{Zc}=$ calcined $\mathrm{ZnO}, \mathrm{AZ}=$ silver doped $\mathrm{ZnO}, \mathrm{ANZ}=$ silver and nitrogen co-doped $\mathrm{ZnO}$.

${ }^{*}$ Values in the parentheses are the average particle size of the photocatalysts obtained from TEM images.

TEM

Figure 3 exhibits the TEM images of Zc, AZ, NZ, and ANZ photocatalysts, respectively. It can easily be seen that these photocatalysts consist of irregular particles. While Zc appeared to exhibit mixture of particles of nanospheres and nanorods, AZ is dominated by nanorods. The remaining two photocatalysts, i.e. NZ and ANZ crystallites are nearly spherical. The average size of the as-synthesized nanoparticles is depicted in Table 1. Though the values of particles size of photocatalysts calculated from Scherrer formula and those obtained from TEM are of the same order, yet their corresponding values differ, quantitatively.

Bull. Chem. Soc. Ethiop. 2013, 27(2) 
a

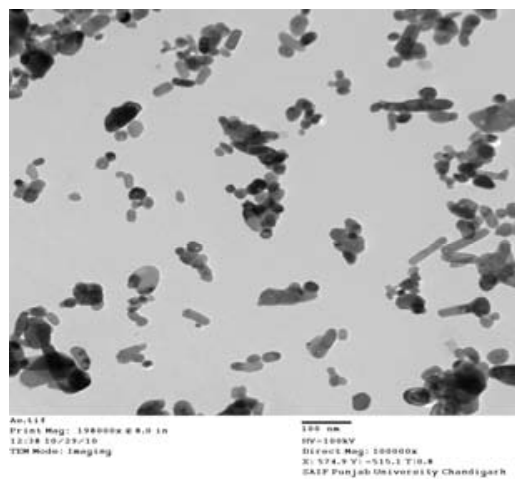

$\mathrm{c}$

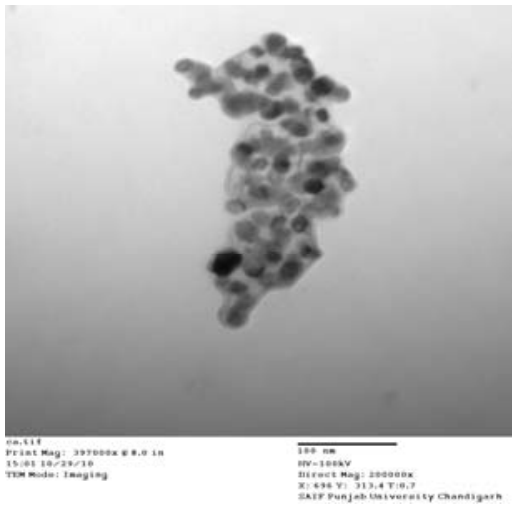

b

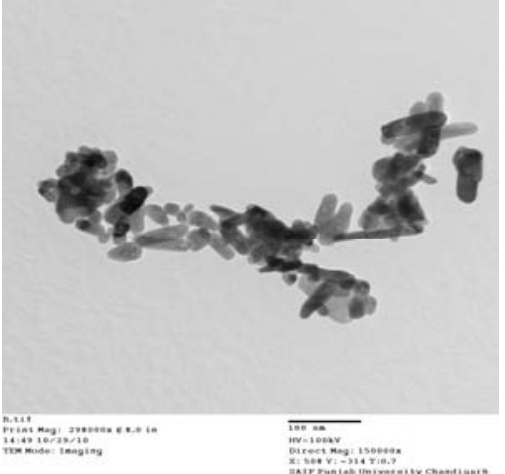

d

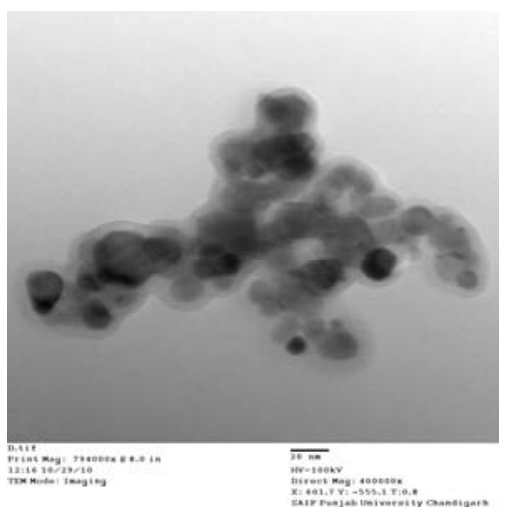

Figure 3. TEM image of (a) calcined zinc oxide (Zc), (b) silver-doped zinc oxide (AZ), (c) nitrogen-doped zinc oxide (NZ) and (d) silver-nitrogen co-doped zinc oxide (ANZ).

\section{UV/Vis diffuse absorption spectra}

UV-Visible diffuse absorption edge of as-synthesized photocatalysts is obtained from the plots of absorbance against wavelength. The interception of the tangent on the descending part of the absorption peak at the wavelength axis gives the value of diffuse absorption edge (nm). UVVisible diffuse absorption spectra and the absorption edge wavelength $(\lambda)$ for the photocatalysts are depicted in Figure 4. Absorption edge wavelength $(\lambda)$ for Zc, AZ, NZ and ANZ are: 379, 402,531 , and $543 \mathrm{~nm}$, respectively. Band gap energies for the as-synthesized photocatalysts were obtained using the relation [21]:

$\mathrm{E}_{\mathrm{g}}(\mathrm{eV})=[1240 / \lambda]$

where $E_{g}$ is band gap energy in electron volts, $\lambda$ is absorption edge wavelength in $\mathrm{nm}$. The calculated band gap energies of photocatalysts Zc, AZ, NZ, and ANZ were found to be 3.27, $3.09,2.34,2.28 \mathrm{eV}$, respectively. 

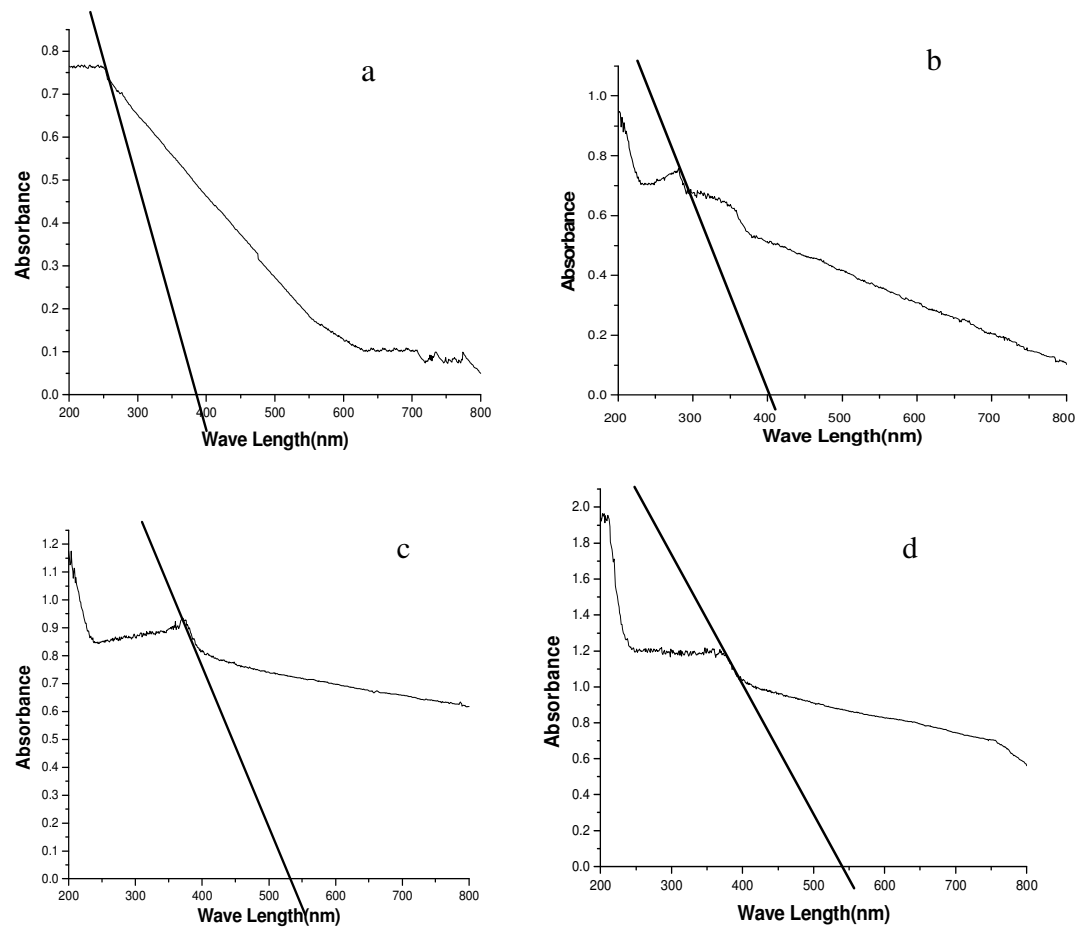

Figure 4. UV-Visible diffuse absorption spectra and the absorption edge wavelength $(\lambda)$ : (a) calcined $\mathrm{ZnO}(\lambda=379 \mathrm{~nm})$, (b) Ag-doped $\mathrm{ZnO}(\lambda=402 \mathrm{~nm})$, (c) $\mathrm{N}$-doped $\mathrm{ZnO}(\lambda=$ $531 \mathrm{~nm}),(\mathrm{d}) \mathrm{Ag}-\mathrm{N}$-doped $\mathrm{ZnO}(\lambda=543 \mathrm{~nm})$.

UV-Vis diffuse absorption edge of NZ and ANZ photocatalysts are well extended to visible region of the spectrum compared to $\mathrm{Zc}$ and $\mathrm{AZ}$. This may be due to the modification of electronic levels of zinc oxide by nitrogen-doping. Doped nitrogen occupies interstitial sites in zinc oxide. More $2 p$ п-electron of nitrogen compared to those of replaced oxygen at the lattice sites create new energy levels between conduction and valence bands of $\mathrm{ZnO}$, thus, decreasing the band gap in zinc oxide [22]. Incorporation of silver in zinc oxide caused comparatively smaller decrease in band gap energy relative to such incorporation of nitrogen. It may be because doped silver simply adheres at the surface of zinc oxide and therefore does not modify the band gap energy of zinc oxide [23]. Silver traps the electrons at the conduction band and prevents electro-hole recombination [24].

\section{Photocatalytic degradation study}

Percent adsorption of methyl red (MR) dye under no-irradiation over Znc, Zc, AZ, NZ, and ANZ at 180 min were $4.6 \%, 7.96 \%, 3.12 \%, 2.3 \%$, and $7.13 \%$, respectively (Figure 5). Percent photodegradation of methyl red (MR) under UV and solar irradiations using as-synthesized photocatalysts, Znc, Zc, AZ, NZ, and ANZ, as a function of time, are presented in Figures 6 and 7 , respectively. The percent degradations under UV irradiation were $11.08 \%, 37.11 \%, 56.62 \%$, $50.95 \%$, and $60.96 \%$, respectively. The percent photodegaradations under solar irradiation were $17.04 \%, 47.06 \%, 74.12 \%, 84.92 \%$, and $91.65 \%$ for Znc, Zc, AZ, NZ, and ANZ phtocatalysts, respectively. The percent photodegradation values of methyl red dye under both UV and solar 
irradiation were obtained after subtracting the corresponding percent adsorption values without irradiation.

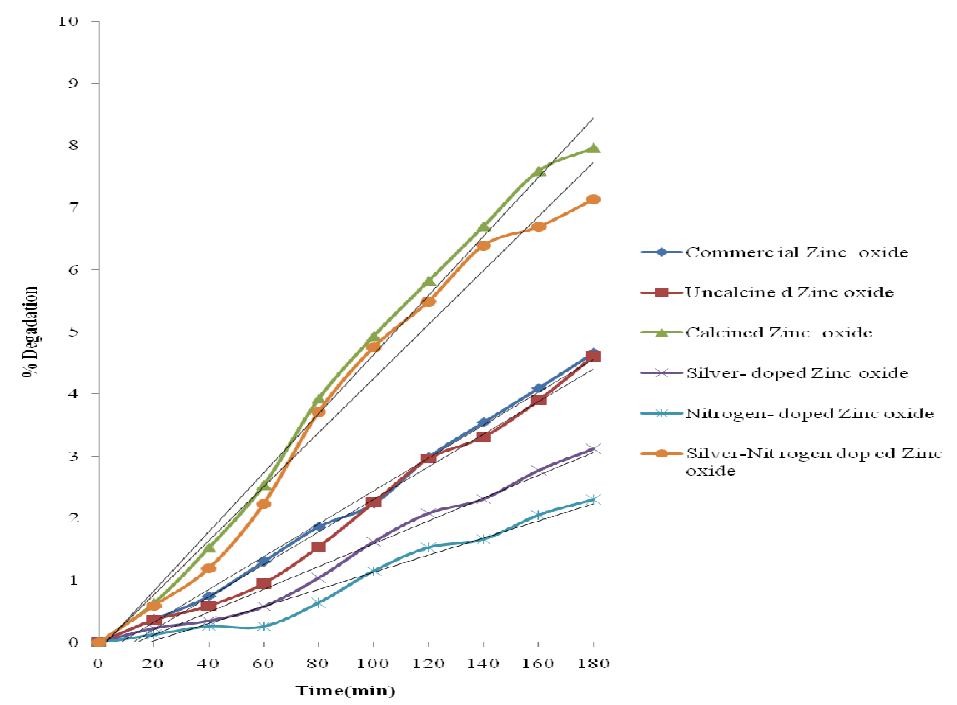

Figure 5. Plots of percentage adsorption of methyl red as a function of time (without irradiation).

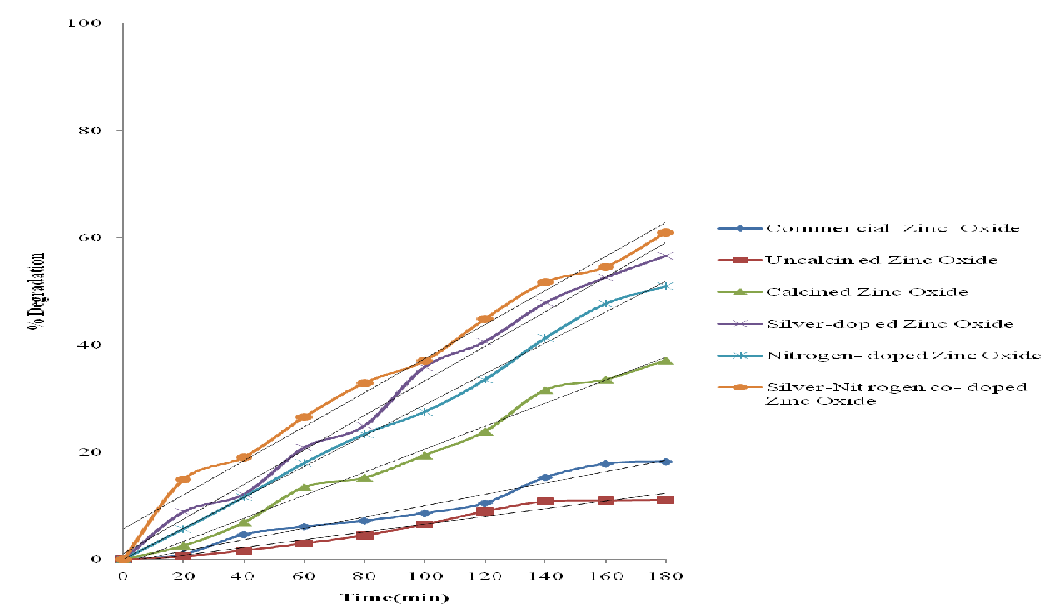

Figure 6. Plots of percentage degradation of methyl red as function of time (under UV irradiation).

The influence of shape on photocatalytic efficiency is pronounced on nanoparticles with diameter less than $20 \mathrm{~nm}$ [25]. For similar diameters, especially at extremely small size, nanorods resulted in more effective separation of electron-hole and higher photocatalytic efficiency compared with nanodots [26] provided that both have either no defect or comparable defect concentrations [27]. In our case, Zc and AZ are nanorod types with particle size of 47 and $44 \mathrm{~nm}$ respectively where as NZ and ANZ samples resulted in nanodots with average

Bull. Chem. Soc. Ethiop. 2013, 27(2) 
particle size of 20 and $16 \mathrm{~nm}$, respectively. For instance, particle sizes of similar shape and size like Zc and AZ or NZ and ANZ showed different photocatalytic efficiency both in UV and solar irradiation (Figures 6 and 7). In general, the particles exhibited large particle size and influence of shape on the photocatalytic efficiency is therefore, presumed to be very less pronounced.

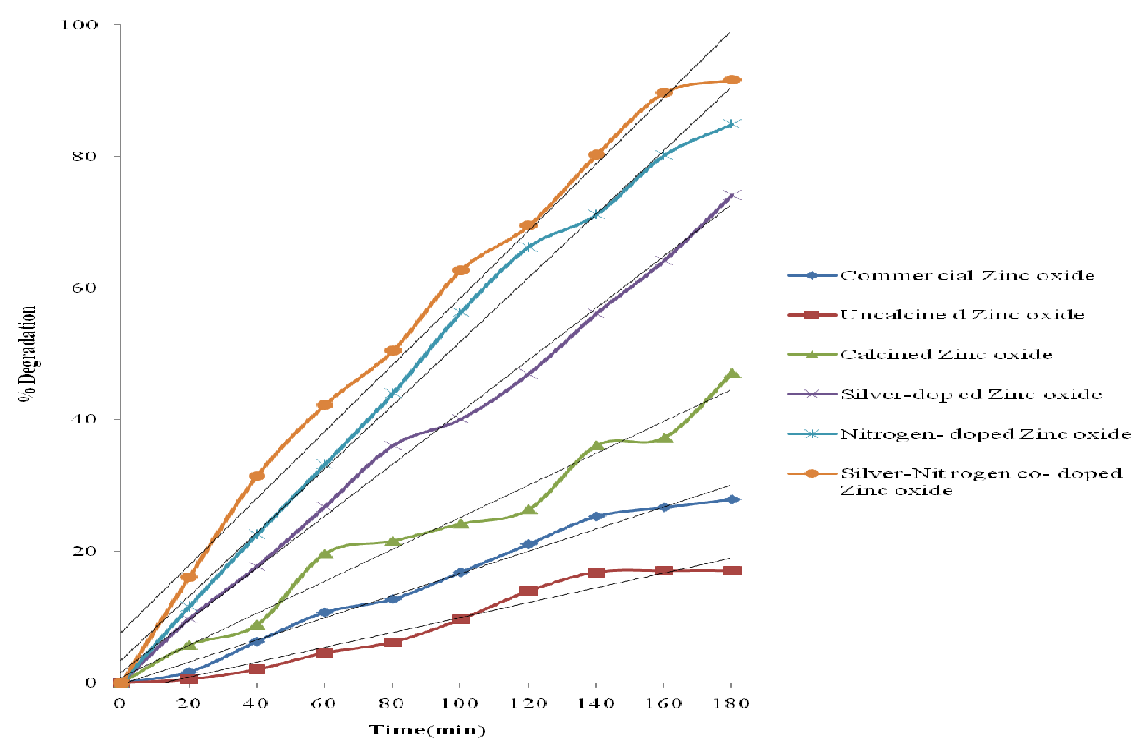

Figure 7. Plots of percentage degradation of methyl red as function of time (under solar irradiation).

Photocatalytic activity of silver doped $\mathrm{ZnO}$ is higher than calcined $\mathrm{ZnO}$ both under solar as well as UV irradiations. It may be because doping of a noble metal, such as silver, in a semiconductor can entrap the photo-generated electron thereby diminishing the recombination of electron-hole pairs, and thus resulting in higher photocatalytic activity of silver doped $\mathrm{ZnO}$. Nitrogen-doped $\mathrm{ZnO}$ shows more photocatalytic activity than calcined $\mathrm{ZnO}$. This may be due to narrowing of band gap energy on doping nitrogen in $\mathrm{ZnO}$. It is also worthwhile to compare the photocatalytic activity of $\mathrm{Ag}$ doped $\mathrm{ZnO}$ and $\mathrm{N}$-doped $\mathrm{ZnO}$. It is observed that under solar irradiations the percentage degradation of $\mathrm{MR}$ is higher for $\mathrm{N}$-doped $\mathrm{ZnO}$ than $\mathrm{Ag}$-doped $\mathrm{ZnO}$. Under UV irradiations the percentage degradation of MR solution is higher for Ag-doped $\mathrm{ZnO}$ than $\mathrm{N}$-doped $\mathrm{ZnO}$. Nonmetals such as nitrogen incorporated in the crystal of zinc oxide, may modify the electronic levels of zinc oxide resulting in its band gap narrowing, thus, rendering it more responsive to solar radiation $[18,22]$. In case of Ag-doped $\mathrm{ZnO}$, under UV irradiations, since silver can trap the photogenerated electron inhibiting the recombination of electron-hole pair and thus enhancing its photocatalytic activity [12]. However, in case of $\mathrm{N}$-doped $\mathrm{ZnO}$, no such species is present to delay the electron-hole recombination and hence resulted to lower efficiency under UV irradiation. The photocatalytic activity of $\mathrm{Ag}-\mathrm{N}$ codoped $\mathrm{ZnO}$ is highest among the studied photocatalysts both under solar as well as UV irradiations. It may be due to the synergetic effect of silver and nitrogen co-doping in enhancing the photocatalytic activity.

Kinetic studies of photocatalytic degradation of $M R$

Kinetics of adsorption of methyl red (MR) under no irradiation and its photocatalytic degradation under UV and solar radiation follow pseudo first order kinetics $\left(R^{2}>0.96\right)$.

Bull. Chem. Soc. Ethiop. 2013, 27(2) 
Adsorption rate constant $(\mathrm{k})$ for adsorption or photocatalytic degradation were obtained using the relation [28]:

$\log \left(\mathrm{C}_{0} / \mathrm{C}_{\mathrm{t}}\right)=(\mathrm{k} / 2.303) \cdot \mathrm{t}$

where, $\mathrm{C}_{0}$ is the initial concentration of methyl red and $\mathrm{C}_{\mathrm{t}}$ is its concentration at time ' $\mathrm{t}$ ', in minutes. Values of the rate constant ' $\mathrm{k}$ ' $\left(\mathrm{min}^{-1}\right)$ were obtained from the slope of linear plot of $\log \left(\mathrm{C}_{0} / \mathrm{C}_{\mathrm{t}}\right)$ as a function of time.

Adsorption rate constant $(\mathrm{k})$ values of methyl red (MR), without irradiation, using photocatalysts: Znc, Zc, AZ, NZ, and ANZ are $2.56 \times 10^{-4}, 3.84 \times 10^{-4}, 1.79 \times 10^{-4}, 1.27 \times 10^{-4}$ and $4.0 \times 10^{-4} \mathrm{~min}^{-1}$, respectively (Figure 6). The observed rate constants (k) for the photocatalytic degradation of MR using different photocatalysts of Znc, Zc, AZ, NZ and ANZ are $9.47 \times 10^{-4}, 3.33 \times 10^{-3}, 5.07 \times 10^{-3}, 4.2 \times 10^{-3}$ and $6.35 \times 10^{-3} \mathrm{~min}^{-1}$ respectively under UV irradiations (Figure 8) and $1.36 \times 10^{-3}, 4.44 \times 10^{-3}, 8.2 \times 10^{-3}, 1.14 \times 10^{-2}$ and $2.23 \times 10^{-2} \mathrm{~min}^{-1}$ respectively under solar irradiations (Figures 8 and 9).

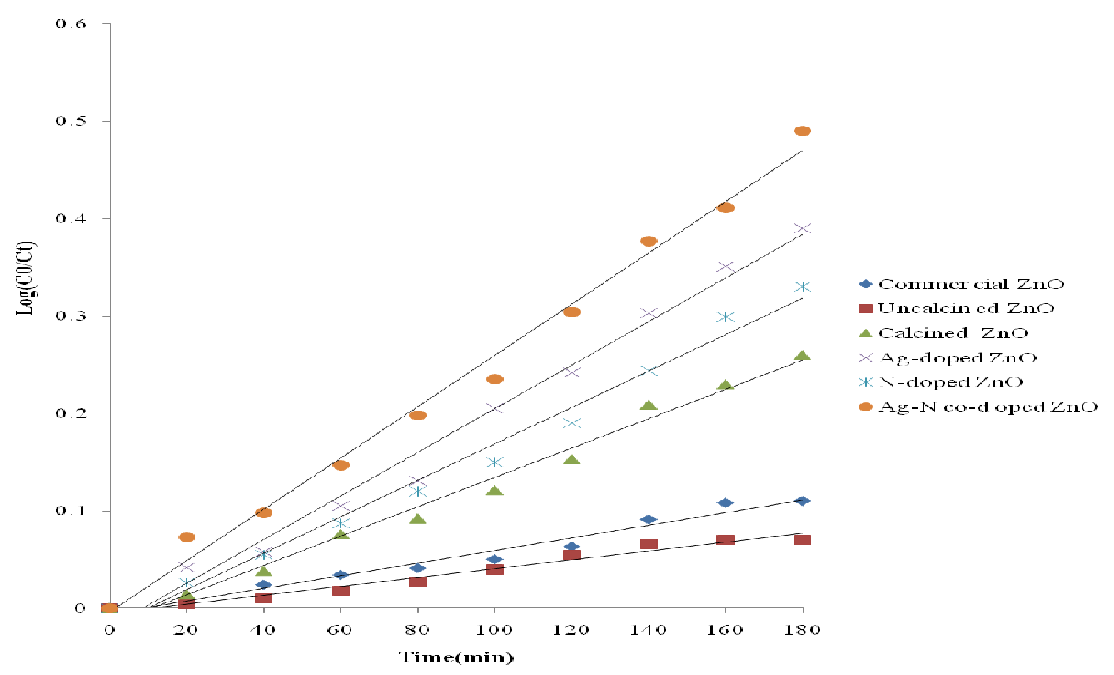

Figure 8. $\log \left(\mathrm{C}_{0} / \mathrm{C}_{\mathrm{t}}\right)$ vs. time curves of photocatalytic degradation of $\mathrm{MR}$ using $\mathrm{ZnO}$ and modified $\mathrm{ZnO}$ photocatalysts (under UV irradiation).

\section{Mechanism of photocatalytic degradation}

The mechanism involved that describes the synergetic effect of silver and nitrogen co-doping in $\mathrm{ZnO}$ towards improving its photocatalytic activity, is depicted in Figure 10. Under UV irradiation, the electrons in the VB of zinc oxide can first be excited to its $\mathrm{CB}$. The excited electrons are trapped by doped $\mathrm{Ag}^{+}$[29] since the $\mathrm{CB}$ is at a more negative potential than $\mathrm{Ag}^{+}$ ion reduction potential. Subsequently, $\mathrm{Ag}^{0}$ is oxidized to its original state $\mathrm{Ag}^{+}$by the adsorbed oxygen and simultaneously producing $\mathrm{O}_{2}{ }^{-}$. The hole combines with water or hydroxyl ion to produce the hydroxyl radical, that cause degradation of dye molecules. The electrons that are originated from the VB of zinc oxide would thus be transported to the adsorbed oxygen, and the recombination of electron and holes is avoided [30, 31]. 


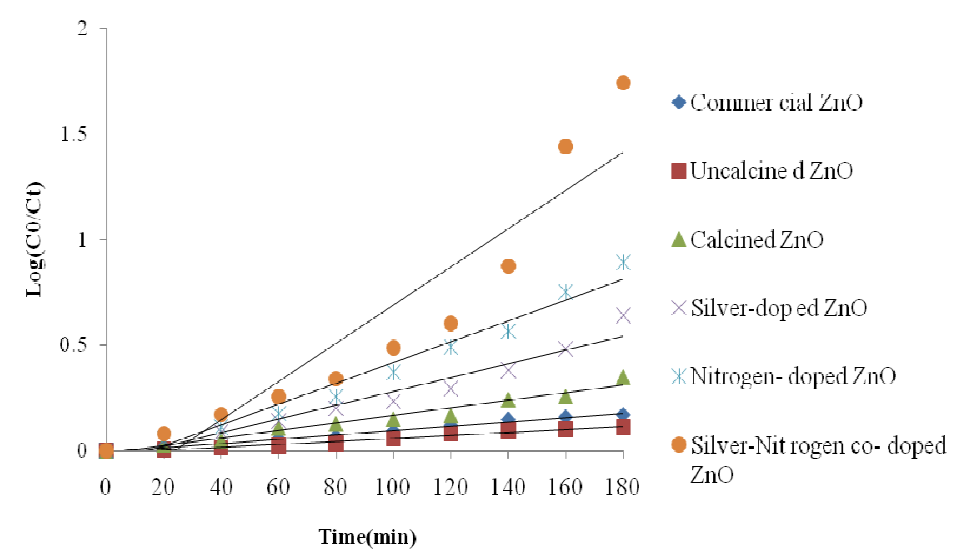

Figure 9. $\log \left(\mathrm{C}_{0} / \mathrm{C}_{\mathrm{t}}\right)$ vs. time curves of photocatalytic degradation of $\mathrm{MR}$ at $\mathrm{ZnO}$ and modified $\mathrm{ZnO}$ photocatalysts (under solar irradiation).

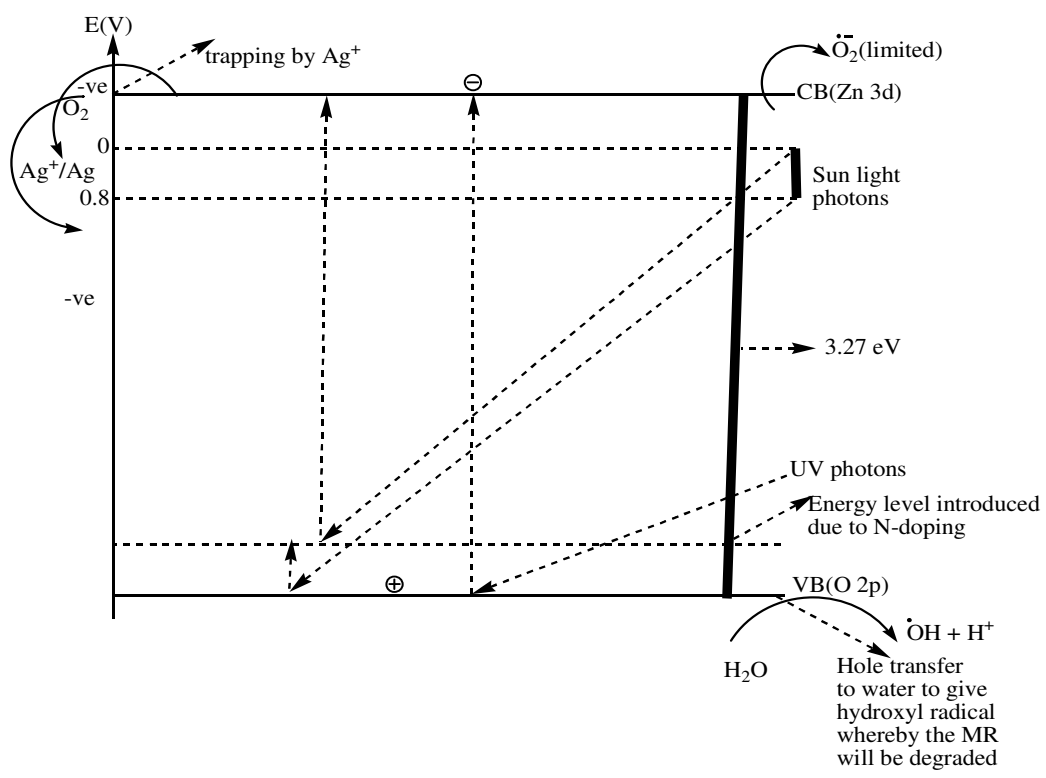

Figure 10. Mechanism of methyl red photodegradation at Ag-N co-doped $\mathrm{ZnO}$.

Due to band gap narrowing in nitrogen-doped $\mathrm{ZnO}$, the excitation of the electrons from the VB, firstly, to the newly formed energy level and then to the conduction band, harvest more visible light photons resulting in higher photo-catalytic activity [22]. The excited electrons are trapped by doped $\mathrm{Ag}^{+}$since the $\mathrm{CB}$ is at a more negative potential than that $\mathrm{fg}^{+}$reduction potential $[30,31]$. Consequently, the recombination of electron and holes is minimized. The positively charged holes left behind at valence band, may combine with water to form hydroxyl radicals which may then oxidize the substrate (dye) to give carbon dioxide and other non-toxic reaction products. 


\section{CONCLUSION}

Nano-size Ag- and/or N-doped zinc oxide have been synthesized and characterized. Assynthesized nano-material have been used for photocatalytic degradation of methyl red (MR) dye in aqueous media, under UV and solar radiations. Doping of nitrogen into zinc oxide modifies the electronic properties of zinc oxide, narrows its band-gap energy, extending its optical absorption to the visible light region. It enables $\mathrm{N}$-doped $\mathrm{ZnO}$ to harvest more photons of solar radiations; thus, improving the photocatalytic activity of the semiconductor. Silver doped zinc oxide showed an enhanced photocatalytic activity for the degradation of MR by facilitating electron-hole pair separation. Ag-N co-doping in zinc oxide had synergetic effect in enhancing its photo-catalytic activity.

\section{ACKNOWLEDGMENTS}

The authors would like to thank Haramaya University for the financial assistance.

\section{REFERENCES}

1. Pekakis, P.A.; Xekoukoulotakis, N.P.; Mantzavinos, D. Water Res. 2006, 40, 1276.

2. Constapel, M.; Schellentrager, M.; Marzinkowski, J. M.; Gäb, S. Water Res. 2009, 43, 733.

3. Chong, M.N.; Jin, B.; Chow, C.W.K.; Saint, C. Water Res. 2010, 44, 2997.

4. Kyung, H.; Lee J.; Choi, W. Environ. Sci. Technol. 2005, 39, 2376.

5. Umar, I. G.; Abdul, H. A. J. Photochem. Photobio. C: Photochem. Rev. 2008, 9, 1

6. Whang Thou-Jen,; Mu-Tao, H. ; Huang-Han, C. Appl. Surf. Sci. 2012, 258, 2796.

7. Shifu, C.; Zhao, W.; Zhang, S.; Liu, W. Chem. Eng. J. 2009, 148, 263.

8. Li, Z.; Suyuan, S.; Xiao, X.; Bin, Z.; Alan, M. Catal. Commun. 2011, 12, 890.

9. Mapa, M.; Gopinath, C.S. Chem. Mater. 2009, 21, 351.

10. Kou, H.M.; Wang, J.; Pan Y.B.; Guo, J.K. Mater. Chem. Phys. 2006, 99, 325.

11. Wang, S.M.; Yang, Z.S.; Lu, M.K.; Zhou, Y.Y.; Zhou, G.J.; Qiu, Z.F.; Wang, S.F.; Zhang, H.P.; Zhang, A.Y.. Mater. Lett. 2007, 61, 3005.

12. Zhang, Y.; Mu, J. J. Colloids and Interf. Sci 2007, 309, 478.

13. Zhou, H., Fan, T.X.; Zhang, D. Mater. Lett. 2007, 100, 322.

14. Jang, Y.H.; Kochuveedu, S.T.; Cha, M.-A.; Jang, Y.J.; Lee, J.Y.; Lee, J.; Kim, J.; Ryu, D.Y.; Kim, D.H. J. Colloids and Interf. Sci. 2010, 345, 125

15. Karunakaran, C.; Rajeswari, V.; Gomathisankar, P. Solid State Sci. 2011, 13, 923

16. Samaele, N.; Amornpitoksuk, P.; Suwanboon, S. Powder Technol. 2010, 203, 243.

17. Mirkhani, V.; Tangestaninejad, S.; Moghadam, M.; Habibi M.H.; Vartooni, A.R. J. Iran. Chem. Soc. 2009, 6, 800.

18. Zheng, M.; Wu, J. Appl. Surf. Sci. 2009, 255, 5656.

19. Xu, C.; Cao, L. Su; Liu, G.W; Qu, X.; Yu, Y. J. Alloys Compd. 2010, 497, 373.

20. Kang, S.Z.; Wu, T.; Li, X.; Mu, J. Colloids and Surfaces A: Physicochem. Eng. Aspects Doi: 10.1016/j.colsurfa.2010.08.029.

21. El-Kemary, M.; El-Shamy, H.; El-Mehasseb, I. J. Lumin. 2010, 130, 2327.

22. Li, D.; Haneda, H. Chemosphere 2003, 54, 1099.

23. Ren, C.; Yang, B.; Wu, V.X.; Fu, J.Z.I.; Guo, Y.T.; Zhao, Y.; Zhu, C. J. Hazard. Mater. 2010, $182,123$.

24. Aal, A.A.; Mahmud, S.A.; Aboul-Gheit, A.K. Mater. Sci. Eng. 2009, $29,831$.

25. Zheng, C.; Jinghai, L.; Song Q.; Graham D.; Wei, C. Catal. Commun. 2012, 21, 1.

26. Nándor, B.; Dávid, F.S.; András, D.; Pál, S.; Károly, M. Appl. Catal. B: Environ. 2010, 96, 569.

27. Sumetha, S.; Pongsaton, A.; Nantakan, M. Ceram. Internat. 2011, 37, 2247.

28. Marto, J.; Marcos, P.S.; Trindade, T.; Labrincha, J.A. J. Hazard. Mater. 2009, 163, 36.

29. Liqiang, J.; Dejun, W.; Baiqi, W.; Shudan, L.; Baifu, X.; Honggang, F.; Jiazhong, S. J. Mol. Catal. A: Chem. 2006, 244, 193.

30. Lu, W.W.; GaO, S.Y.; Wang, J.J. J. Phys. Chem. C 2008, 112, 16792.

31. Xu, Y.; Xu, H.; Li, H.; Xia, J.; Liu, C.; Liu, L. J. Alloys Compd. 2011, 509, 3286. 